\title{
WAVE LOADS ASSESSMENT FOR SUBMERGED WATER INTAKE DESIGN
}

\author{
Shen Daoxian D.; Kauffman Alicia, CH2M-JACOBS, 22 Cortlandt St., New York, NY 10007, USA \\ Zhang Yang, CH2M-JACOBS, 4350 W. Cypress St, Tampa, FL 33647 USA
}

Cornett Andrew, National Research Council (NRC),1200 Montreal Rd., Building M32, Ottawa, Ontario, K1A OR6, Canada

\section{INTRODUCTION}

Estimating wave-induced forces on water intake is challenging, particularly for large size intake (up to $15 \mathrm{~m}$ in its cap diameter) subject to breaking waves in shallow water. The relationships between wave properties and wave loads are not well understood, and no simple methods are available to predict hydrodynamic loads on submerged intakes, particularly under breaking waves.

This paper attempts to provide a method of assessing wave forces on water intake pipe and velocity cap using the Froude-Krylov formula, based on physical modeling test results for submerged intake under breaking waves.

\section{METHODOLOGY AND RESULTS}

There has been considerable research in the past decades on wave loads on cylinder structures. However, relatively few (Cornett, 2015) has studied velocity caps exposed to highly nonlinear oscillatory flows. If neither separation nor reflection occur on the structure, FroudeKrylov (F-K) theory can be used for small to large size pipe and circular disco in a wide range compared with Morrison equation method when the inertia force predominates. Therefore, this paper will focus on the F-K theory for the estimate of the intake forces in the concept level design.

The F-K force formula by Chakrabarti (1999) is based on linear wave theory. Submerged intakes in shallow water are often subject to highly nonlinear, breaking waves, and the F-K formula may not be accurate but easy for the designer to use. For instance, the F-K formula for horizontal force on the vertical cylinder is: $F_{x}=$ $C_{H} \rho V \frac{2 J_{1}(k a)}{k a} \frac{\sinh \left(\frac{k l}{2}\right)}{\frac{k l}{2}} u_{0}^{\prime}$, in which $a$ is the pipe radius, $k$ the wave number, / the pipe length, $u_{0}^{\prime}$ the water particle horizontal acceleration, and $J$ is the Bessel function, $C_{H}$ the force coefficient. The key issue is to get relative "reliable" force coefficient to estimate the wave forces.

The current study approach is to (a) collect the wave force data from physical modeling studies on the water intakes; and develop the empirical relations of peak wave loads in terms of characteristic wave parameters based on experiment data; (b) develop the empirical relations of force coefficients $\left(C_{H}, C_{v}\right)$ in terms of characteristic wave parameters based on the same data.

The data used in this study are from three 2D-physical modeling studies on water intake projects. First one is from NRC, Canada (Cornett A, 2015); the second one is for an intake Project at Mexico and the last one is for one UAE project. The Mexico project intake structure consists of a pipe with $1.9 \mathrm{~m}$ diameter, $2 \mathrm{~m}$ high above a concrete pad, and a $4.6 \mathrm{~m}$ wide by $0.33 \mathrm{~m}$ thick octagonal velocity cap. The intake is located at $-5.8 \mathrm{~m}$ CD location. The NRC intake has a $2.1 \mathrm{~m}$ diameter and $2.3 \mathrm{~m}$ high pipe, and a
$5.2 \mathrm{~m}$ circular cap. The intake is located at $-9.5 \mathrm{~m}$ Mean Water Level location. The UAE project intake consists of a pipe with $8.0 \mathrm{~m}$ diameter and $8.7 \mathrm{~m}$ height above a concrete pad, and a diameter $15 \mathrm{~m}$ circular cap with its $0.4 \mathrm{~m}$ thick. The intake is mostly buried under seabed $-7.5 \mathrm{~m} \mathrm{~m}$ CD.

The first two physical models were performed by $\mathrm{NRC} / \mathrm{CHC}$ at a $2.0 \mathrm{~m}$ wide by $97 \mathrm{~m}$ long by $2.9 \mathrm{~m}$ deep wave flume, with scale of 1:13 (Mexico) and 1:15 (NRC). The last one was performed in other nation at a $5 \mathrm{~m}$ wide by $456 \mathrm{~m}$ long by $12 \mathrm{~m}$ deep flume, with scale of $1: 8$.

The major test conditions for the Mexico project intake are shown in Table 1. The test conditions for $\mathrm{CHC}$ intake were a combination of three water depth of $7.5 \mathrm{~m}, 9.5 \mathrm{~m}, 11.5$ $\mathrm{m}$, with three peak periods $T_{p}$, of 8.0, 11.0 and $14.0 \mathrm{~s}$ and three significant wave heights $H_{s}$, of $3.0,4.5$ and $6.0 \mathrm{~m}$ (27 cases). The UAE test conditions was limited for 4 cases of significant wave heights of $4.1 \mathrm{~m}, 3.3 \mathrm{~m}, 3.1 \mathrm{~m}$ and $2.5 \mathrm{~m}$ with perk period of $10.5 \mathrm{~s}$ and $9 \mathrm{~s}$.

\begin{tabular}{clllll}
$\begin{array}{c}\text { Ca } \\
\text { se }\end{array}$ & $\begin{array}{l}\text { Water } \\
\text { level }\end{array}$ & $\begin{array}{l}\text { Offshor } \\
\boldsymbol{e}(\mathrm{Hs})\end{array}$ & $\begin{array}{l}\text { Offshor } \\
\boldsymbol{e}(\mathrm{Tp})\end{array}$ & $\begin{array}{l}\text { Intake } \\
(\mathrm{Hs})\end{array}$ & $\begin{array}{l}\text { Intake } \\
\text { (Hmax) }\end{array}$ \\
\hline 1 & $0.0 \mathrm{~m}$ & $6.1 \mathrm{~m}$ & $12 \mathrm{~s}$ & $5.3 \mathrm{~m}$ & $7.9 \mathrm{~m}$ \\
2 & $0.0 \mathrm{~m}$ & $5.8 \mathrm{~m}$ & $12 \mathrm{~s}$ & $5.2 \mathrm{~m}$ & $7.6 \mathrm{~m}$ \\
3 & $0.0 \mathrm{~m}$ & $6.0 \mathrm{~m}$ & $9 \mathrm{~s}$ & $4.7 \mathrm{~m}$ & $6.4 \mathrm{~m}$ \\
$\mathbf{4}$ & $2.2 \mathrm{~m}$ & $5.0 \mathrm{~m}$ & $12 \mathrm{~s}$ & $5.9 \mathrm{~m}$ & $8.8 \mathrm{~m}$ \\
5 & $2.2 \mathrm{~m}$ & $4.8 \mathrm{~m}$ & $9 \mathrm{~s}$ & $5.2 \mathrm{~m}$ & $7.7 \mathrm{~m}$ \\
6 & $2.2 \mathrm{~m}$ & $5.0 \mathrm{~m}$ & $14 \mathrm{~s}$ & $7.4 \mathrm{~m}$ & $11.7 \mathrm{~m}$ \\
\hline
\end{tabular}

Table 1: Main Test Conditions for Mexico Project Intake

The first two models provide the minimum and maximum force values $\left(F_{\min }, F_{\max }\right)$ and associated with low occurrence probability, such as the 95-percentile $F_{95}, F_{98}$, and $F_{9 g}$ values. In this paper, the $F_{95}$ statistic, defined as the 95-percentile value, has been adopted to characterize the extreme forces by irregular waves.

The force data were obtained from different ways between the first two models and the third, but all are converted to the same system. The vertical uplift force at the top cap was converted into the "pressure" by dividing with its cap projection area in vertical direction, and the horizontal force at the pipe by dividing its area in horizontal direction.

The ratio of the significant wave height $\left(H_{s}\right)$ at the intake to the local water depth $(h)$ varied from 0.24 to 0.90 , where " $\mathrm{h}$ " is local water depth. Figure 1 shows the variation in peak vertical uplift force (pressure) $P_{z, 95}$, versus local $H_{m o} / h$ for all three physical models at the top caps. Despite the relatively scatter, there is a clear trend of increasing peak force with increasing the ratio of the significant wave height over water depth. The observed variation of peak uplift force (pressure) with $H_{m o} / h$ can be described by a simple exponential equation as shown in Figure 2. 


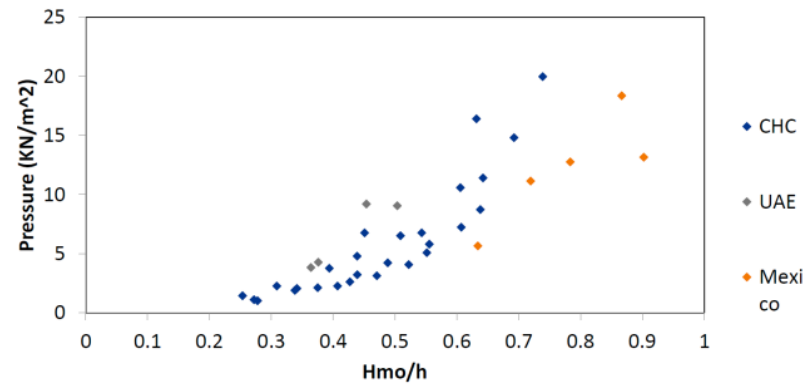

Figure 1 Uplift "pressure" vs. Hmo/h for intake caps

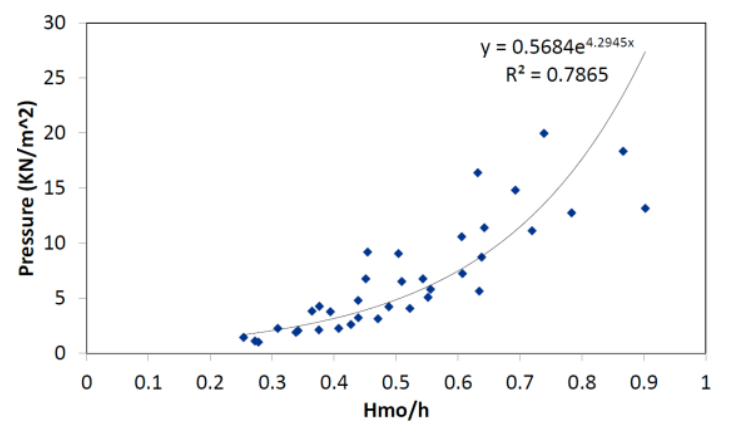

Figure 2 Empirical relations of uplift "pressure" vs. Hmo/h for intake caps

Figures 3 and 4 show the variation in peak horizontal force (pressure), $P_{X, 95}$, versus local $H_{m o} / h$ for the two models at the

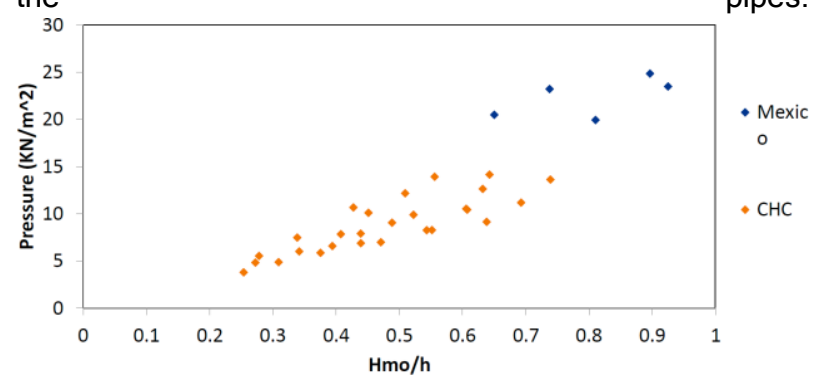

Figure 3 Horizontal "pressure" vs. Hmo/h for the pipes

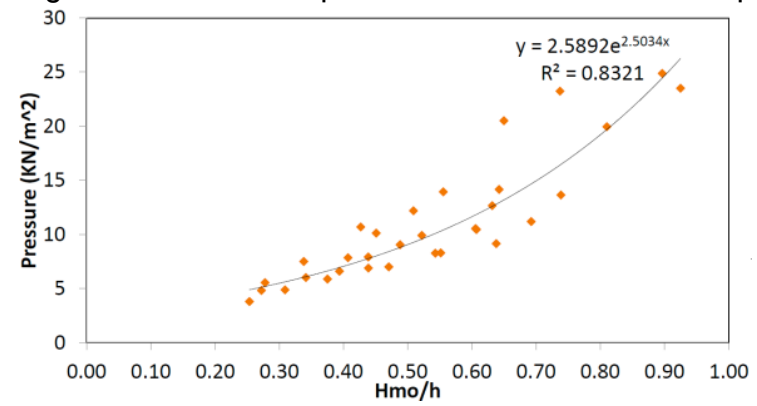

Figure 4 Empirical relations of horizontal "pressure" vs. $\mathrm{Hmo} / \mathrm{h}$ for the pipes/cylinders

The parameter ka range, was investigated based on the model data. The $k a$ ranges from 0.11 to 0.63 which is applicable to F-K theory, but mostly not for Morison equation. The force coefficients were back-calculated from the modeling results. Figures 5 and 6 show the variation in vertical coefficient $C_{V}$ versus local $H_{m o} / h$ for the cap, and Figure 7 shows correlations of the coefficient $\mathrm{CH}_{H}$ with local $H_{m o} / h$ for the pipe.

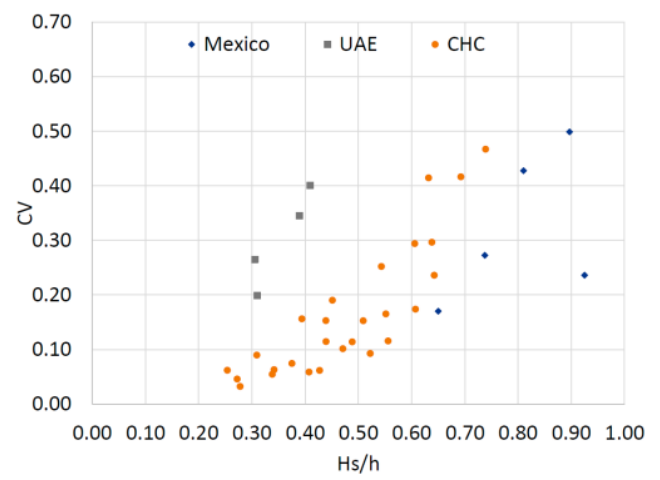

Figure 5 Force coefficient Cv vs. Hmo/h for intake caps

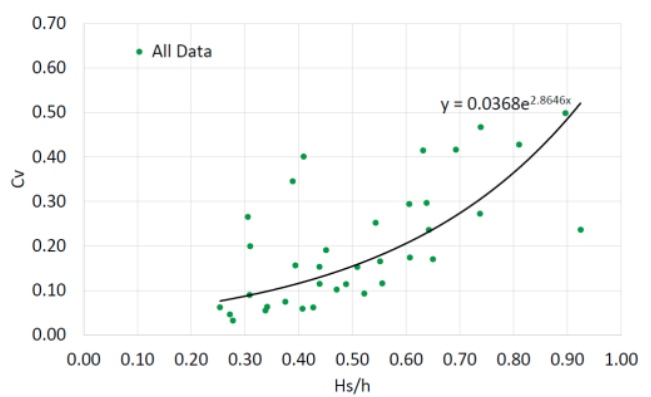

Figure 6 Correlation of Force coefficient Cv vs. Hmo/h for intake caps

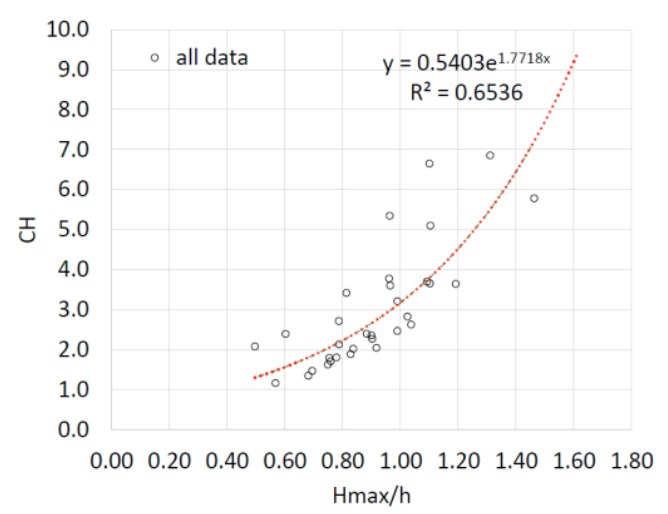

Figure 7 Correlation of Force coefficient $C_{H}$ vs. Hmo/h for intake pipes

\section{PRELIMINARY CONCLUSIONS}

This paper attempts to provide a practical approach of estimating wave forces on the submerged intake subject to breaking waves for concept design based on three 2D physical model studies. The empirical correlations of peak vertical uplift and horizontal wave forces/pressures versus local $H_{m o} / h$ were developed and furthermore, the empirical correlations of force coefficients $\left(C_{H}, C_{v}\right)$ versus local $H_{m o} / h$ were also introduced using the Froude-Krylov formulas.

\section{REFERENCES}

Cornett A., Hecimovich M., Nistor I; Extreme wave loads on submerged water intakes in shallow water. Journal of Hydrodynamics, 27(1), February 2015. 